\title{
«RESISTIR LA IMPOSICIÓN»: REVOLUCIÓN, CIUDADANÍA Y REPÚBLICA EN LA ARGENTINA DE $1880^{1}$
}

POR

\author{
HILDA SÁBATO
}

Universidad de Buenos Aires/CONICET

La revolución que tuvo lugar en 1880 en Buenos Aires fue un acontecimiento decisivo en la historia de la Argentina. Este trabajo aborda una dimensión de ese conflicto, la que se refiere a la disputa por el sentido que los contemporáneos dieron al término «revolución» en el contexto de los lenguajes políticos vigentes. Para dar cuenta de ella, indaga en los argumentos que pautaron la retórica de los revolucionarios, así como en los que estuvieron en la base de la impugnación a sus acciones.

Palabras clave: Revolución, ciudadanía política, fuerzas militares, República, lenguajes políticos.

«De todas las guerras que ocurrieron en este país a lo largo de muchos años, la presente es la más decisiva, pues establece de manera incontestable la autoridad y la supremacía del gobierno nacional, su fuerza superior y sus abundantes recursos frente a la revolución, aun cuando esa revolución sea llevada adelante por la provincia más poblada y más influyente de la Confederación argentina.»

Con estas palabras, The Standard, uno de los diarios más respetados de Buenos Aires, anunciaba la conclusión de un conflicto que había agitado las aguas de la política argentina durante varios meses hasta terminar en un en-

1 Este artículo forma parte de los resultados de una investigación sobre la violencia política en la segunda mitad del siglo XIX en la Argentina, que cuenta con el apoyo de la Universidad de Buenos Aires (programa UBACyT) y del FONCyT/ANPCyT (PICT 13934 y 420). En la búsqueda, selección y recolección de información he contado con la colaboración invalorable de Graciela Bonet y Juan José Santos.

2 The Standard, Buenos Aires, 7 de julio de 1880 [trad. HS]. El diario se publicaba en inglés y se consideraba el vocero de la colectividad británica local. 
frentamiento armado de envergadura ${ }^{2}$. No era la primera vez, ni sería la última, que una disputa política buscaba dirimirse en el campo de batalla, pero la «revolución» de 1880 fue, por diversas razones, un acontecimiento decisivo en la historia de la república. Algunas de esas razones irán saliendo a luz a lo largo de este artículo, cuyo asunto principal será, sin embargo, más acotado. Me interesa, sobre todo, indagar en la retórica que sirvió de fundamento a la práctica de la revolución, así como en la que se utilizó para justificar su represión.

\section{EL AÑO 1880}

Como en tantos otros levantamientos armados en la Hispanoamérica del siglo XIX, éste se originó en una disputa de índole electoral. En 1880 los argentinos debían elegir al sucesor de Nicolás Avellaneda, presidente que cumplía entonces sus seis años reglamentarios de mandato 3 . Desde tiempo antes habían comenzado las negociaciones en torno a las candidaturas, pero fue a mediados de 1879 cuando se afirmaron dos nombres, los de Julio A. Roca y Carlos Tejedor ${ }^{4}$. Los meses que siguieron a esa definición fueron turbulentos, pues la contienda no sólo dio lugar a las movilizaciones habituales en tiempos de elección, sino que alimentó conflictos violentos en varios lugares del país y una última confrontación armada en la provincia de Buenos Aires.

Para entonces, hacía casi treinta años que la Constitución de 1853 había establecido los parámetros de la organización institucional de la república y veinte desde que ésta había alcanzado la unificación política efectiva. Sin embargo, esa unidad no había dado paso a la centralización de la actividad política ni de sus estructuras, las que seguían teniendo su sede principal en las provincias. Allí se construía y reproducía el poder local a partir de tradiciones, es-

3 Dado que el sistema era indirecto, primero se realizaban los comicios para integrar el Colegio Electoral y luego éste debía designar la fórmula ganadora, que duraba seis años en el cargo sin que pudiera postularse a la reelección.

4 Carlos Tejedor (1817-1903) era un reconocido jurista con experiencia en la gestión estatal y en la cátedra universitaria. Desde 1878 era gobernador de la provincia de Buenos Aires, por una alianza entre el Partido Autonomista al que pertenecía - al igual que el presidente Avellane$\mathrm{da}$ - , y el Partido Nacionalista, dirigido por el prestigioso dirigente porteño y ex presidente (1862-1868), Bartolomé Mitre. Su candidatura a presidente fue sostenida por una coalición de fuerzas de los dos partidos. Julio Argentino Roca (1843-1914) era por entonces ministro de Guerra en el gabinete nacional, un joven pero ya conocido militar de carrera, que había ascendido a partir de sus éxitos en sucesivas campañas y había establecido importantes contactos políticos en todo el interior del país. Su candidatura fue levantada por un amplio sector del partido Autonomista, que más tarde adoptó el nombre de Partido Autonomista Nacional (PAN). 
tilos y prácticas propias a cada una de ellas. Y si bien durante esas décadas hubo intentos de proyección de algunos poderes provinciales sobre otros, de construcción de entramados partidarios e institucionales más amplios y de articulación a escala nacional, era en el seno de cada provincia donde las dirigencias tenían sus bases operativas y construían el capital político que les permitía luego jugar en otros ámbitos.

Para ganar una elección presidencial se requería, por lo tanto, asegurar las llamadas «situaciones provinciales» y los diferentes grupos que se disputaban el poder buscaban operar para alcanzar el control institucional y de los recursos electorales locales. Como era habitual, en esta ocasión los movimientos destinados a ganar terreno en cada provincia comenzaron con bastante anticipación a la fecha prevista de los comicios, y a partir de la definición de los candidatos, a mediados de 1879, las disputas locales se agudizaron. En poco tiempo, la mayoría de las provincias se tiñeron con los colores del roquismo.

En el mapa heterogéneo de las catorce provincias, la de Buenos Aires tenía un lugar distintivo. No sólo era la más rica, extensa y poblada, sino que su capital, la ciudad del mismo nombre, era el principal centro financiero, administrativo y cultural del país y albergaba a los poderes del gobierno federal, huésped de la provincia. Su elite política jugaba, además, un papel central en la dirigencia nacional. Allí tenía su principal campo de acción el partido Nacionalista, dirigido por Bartolomé Mitre, y buena parte del Autonomista, del cual provenían el presidente de la república y varios de sus ministros así como el propio gobernador Tejedor ${ }^{5}$. Su candidatura a la presidencia dividió al partido, muchas de cuyas figuras principales (incluido Avellaneda) se inclinaron por la de Roca. Pero en la provincia de Buenos Aires esta última encontró una dura oposición, en la medida en que importantes sectores del autonomismo local, en conjunción con el nacionalismo, sostuvieron la de Tejedor. Esta confrontación de candidaturas escaló hasta desembocar en una revolución que movilizó a amplios sectores de la población y culminó en un enfrentamiento armado entre dos ejércitos de más de diez mil hombres. Si bien ambos contendientes reclamaron el triunfo en el campo de batalla, las armas nacionales llevaron ventaja y hubieran podido continuar la lucha hasta la derrota final de los porteños, pero sus jefes eligieron el camino de la política para doblegar definitivamente a los rebeldes, imponer la autoridad del gobierno central y subordinar la provincia al Estado nacional.

5 Al usar la palabra «partido» retomo la denominación que los contemporáneos daban a sus organizaciones político-electorales, cuyas características eran muy diferentes a las de los partidos políticos actuales. Sobre esos «partidos» véase, entre otros, Sábato, 1998 y Palti, 2007. 
Dada la contundencia del desenlace, tan bien sintetizados en la cita del The Standard que encabeza estas páginas, la mirada de los estudiosos se ha dirigido, sobre todo, a los resultados de este episodio. El levantamiento se analiza en relación con el proceso de afirmación del Estado, un Estado cuya construcción había sido conducida inicialmente por una elite originada en Buenos Aires que no había sido capaz, sin embargo, de consolidar su poder y lo estaba perdiendo en manos de una nueva constelación política con base en los gobernadores de las provincias del interior y centro en el propio aparato estatal. Cuando en el año 1880 aquella elite en decadencia vio peligrar su lugar con la candidatura Roca, sus miembros no dudaron en emprender «el camino de la resistencia armada», camino sin retorno que terminaría por confirmar su ocaso $^{6}$. De esa manera, el Estado nacional triunfó sobre la última provincia con arrestos de autonomía y fortaleció decisivamente su organización y sus instituciones. En el plano político, la presidencia de Roca logró consolidar un nuevo régimen, que prometía poner fin a la gimnasia partidaria propia de los años anteriores y traer «paz y administración» ${ }^{7}$.

En la mayor parte de las interpretaciones sobre el ochenta, sin embargo, el hecho revolucionario mismo no ha sido interrogado. El recurso a las armas para dirimir el conflicto se ha tomado en general como un dato que no requiere explicación, como un resultado esperable de la agudización de la disputa política. Esa cuestión ha sido, en cambio, el centro de mis preocupaciones recientes que me han llevado a la pregunta de por qué se recurrió a la fuerza como medio de acción política ${ }^{8}$. A poco andar encontré que también para los contemporáneos la solución armada representó un problema y que el conflicto del ochenta fue, entre otras cosas, una disputa en torno a la figura de «la revolución». A indagar en esa disputa están dedicadas las páginas que siguen.

\section{REVOLUCIÓN}

«Entre 1810 y 1905 el siglo XIX argentino está plagado de revoluciones.» Estas sintéticas palabras de Carlos Malamud dan cuenta de un hecho que ha sido una y otra vez registrado por la historiografía y que hoy es materia de renovada interrogación en consonancia con la expansión y los cambios que está experimentando la historia política de América Latina. Trabajos recientes ex-

\footnotetext{
6 La expresión es de Botana, 1977: 34.

7 Los análisis más agudos sobre este tema en Botana, 1977, Halperin Donghi, 1980 y Oslak, 1982

8 Sábato, 2008.
} 
ploran levantamientos, rebeliones y guerras civiles como formas de acción política y se preguntan por los sentidos que esos fenómenos tenían en el contexto de la época y para los propios contemporáneos 9 .

Así, se ha rastreado el concepto mismo de «revolución» en el seno de los lenguajes políticos del período. La coexistencia de diferentes maneras de entender la revolución y de articularla con otras categorías políticas en uso alimentó disputas por el sentido y por la valoración de las acciones realizadas en su nombre. En sus distintas variantes, sin embargo, esa noción distaba bastante de la que, surgida de las interpretaciones sobre la Revolución Francesa, alcanzó su predominio en el siglo XX. Si a partir de ella solemos asociar el término con una transformación de estructuras, trabajos recientes sobre América Latina señalan que en buena parte del siglo XIX, en cambio, la noción de «revolución» refería a la restauración de un orden originario. Y remitía al derecho a la resistencia frente al despotismo: cuando los gobernantes abusaban del poder, el pueblo tenía no sólo el derecho sino la obligación, el deber cívico, de hacer uso de la fuerza para restaurar las libertades perdidas y el orden presumiblemente violado por el déspota. Esta concepción - en sus diversas variantesse vinculaba con viejas convicciones pactistas y de cuño iusnaturalista, a la vez que se realimentaba con motivos provenientes de las matrices liberal y republicana. Mientras en el plano discursivo se articulaba con otros conceptos clave, como los de representación, ciudadanía y opinión pública, en el de las prácticas, la acción revolucionaria formó parte del entramado de la vida política en toda la región.

La revolución de 1880 puede, en principio, inscribirse en este marco general, a la vez que se enlaza con la historia particular de Buenos Aires y del conjunto de la Argentina. En la segunda mitad del siglo XIX, la provincia fue el epicentro de varios levantamientos armados contra el poder central de turno. En cada caso, sus protagonistas hablaron de «revolución», una denominación con frecuencia objetada por quienes los acusaban de provocar, más bien, una simple revuelta. El primero de esos episodios, la revolución de 1852, fue por cierto bastante diferente de los restantes, entre otras cosas porque fue el único que resultó triunfante. Tuvo, además, un impacto muy fuerte sobre los siguientes pues constituyó una referencia mítica, una cantera de consignas, símbolos y representaciones para los revolucionarios del resto del siglo. Tanto en ese

9 Sobre este tema, para América Latina, ver los siguientes libros colectivos: Malamud y Dardé (eds.), 2004; Earle (ed.), 2000; Dunkerley (ed.), 2002; Forte y Guajardo (coords.), 2000 y Chust y Marchena (eds.), 2007. Para el caso argentino, segunda mitad del siglo XIX, ver Alonso, 2000; Botana y Gallo, 1997; Malamud, 1998, 2000, 2000a; Sábato Hilda XII/ 23 (Buenos Aires, 2002) y Sábato, 2008. 
como en los demás levantamientos los protagonistas actuaron en nombre de la libertad y los derechos del pueblo, conculcados por un gobierno considerado despótico. Según la retórica de los revolucionarios era «el pueblo de Buenos Aires» el que se levantaba por legítimo derecho; más aún, cumpliendo su deber cívico.

Esta tradición política tuvo, sin embargo, sus impugnadores y hacia 1880 la figura misma de la revolución, y otras estrechamente asociadas a ella, como la de «ciudadanía en armas», comenzaron a ponerse seriamente en cuestión en el marco de cambios importantes en las formas de entender la política. Esas diferentes visiones estuvieron en el seno del conflicto desatado ese año, por lo que una exploración de las valencias que los distintos actores dieron al término de «revolución» puede arrojar luz sobre una dimensión clave de lo ocurrido: la disputa por el sentido de las palabras. Para intentar dar cuenta de esa disputa, en lo que sigue indagaré en los argumentos que pautaron la retórica de los revolucionarios, así como en los que estuvieron en la base de la impugnación a sus acciones.

\section{LIBERTAD ELECTORAL}

«Lo que vosotros quereis lo quiero yo tambien. Seré uno de vosotros para resistir en nuestra querida patria el imperio de la fuerza y del fraude. Concurriré con vosotros, dentro del juego legítimo de nuestras instituciones, á sostener las libertades públicas donde ellas peligren.»

Estas palabras formaron parte del mensaje del gobernador Tejedor a la convención nacional de delegados de los partidos conciliados, el $1 .^{\circ}$ de junio de 1879, cuando aceptó su postulación como candidato a presidente. Ellas enunciaban ya una cuestión que habría de convertirse en consigna principal de su discurso político en los meses siguiente: frente a la fuerza ejercida por el gobierno nacional para imponer su propio candidato y el fraude electoral que no dudaría en realizar para asegurar ese triunfo, el camino era la resistencia. Correspondía así al pueblo de Buenos Aires «dar el ejemplo á los otros pueblos de la República, tan amenazados como nosotros, y con menos medios de resistir»». De esta manera, quedaba la provincia ocupando un lugar que reclamaba con frecuencia, como líder del conjunto de la república frente a quienes pretendieran vulnerar sus libertades. Tejedor prometía sumarse a esa causa, sirviéndola como uno más, pues «caeré ó me levantaré con vosotros...»10.

10 Tejedor, 1881: 54-55. 
Fue un discurso de campaña, combativo, pero que no giró en torno a la disputa con otros candidatos, sino que puso el acento en las amenazas a la «libertad pública» por parte, presumiblemente, del gobierno nacional (el que sin embargo no fue mencionado de manera explícita). Retomó un tema que reiteradamente se hacía presente en el debate público, el del «fraude» electoral. Las elecciones ocuparon un lugar central en la vida política de la Argentina decimonónica $\mathrm{y}$, en las décadas que siguieron a la unificación nacional de $1861 / 1862$, todos los años se realizaban comicios para llenar los cargos representativos en los diferentes niveles de gobierno. La actividad electoral involucraba a sectores diversos de la población según reglas de juego establecidas tanto por las leyes como por las costumbres políticas de la época. Hacia 1880 existían ya mecanismos conocidos y practicados por quienes participaban de la acción partidaria, una especie de gimnasia electoral en la que los límites entre el respeto y la violación de las normas establecidas eran lábiles y, por lo tanto, siempre discutibles. El sistema, sin embargo, funcionó con relativa eficacia, aunque en cada ocasión los perdedores pusieran en cuestión la legalidad de las acciones llevadas adelante por sus adversarios triunfantes e intentaran, por lo tanto, impugnar la legitimidad de los resultados. Se hablaba, entonces, de $«$ fraude $»{ }^{11}$.

Acusaciones de ese tenor acompañaron a casi todas las elecciones del período y si bien en la mayoría de los casos no tuvieron demasiadas consecuencias, en ocasiones se convirtieron en el fundamento central de la resistencia armada. Ése fue el origen de diversos levantamientos, así como de un episodio mayor, que puso en jaque el orden nacional: la revolución de 1874. En esa oportunidad, llegó a la presidencia de la República Nicolás Avellaneda, apoyado por una fuerza integrada por grupos de diferentes provincias y que incluyó al partido Autonomista de Buenos Aires. Los nacionalistas, derrotados, se levantaron en armas pues acusaron a los vencedores de cometer fraude en los comicios para diputados al Congreso, realizados poco antes, y al gobierno de convalidarlos. La proclama que su dirigente máximo, el ex presidente Mitre, dio a conocer en vísperas del alzamiento era elocuente: «... la revolución era un derecho, un deber y una necesidad y... no ejecutarla, con pocos o con muchos, aunque no fuese más que para protestar varonilmente con las armas en la mano, sería un oprobio que probaría que éramos incapaces e indignos de guardar y merecer las libertades perdidas ${ }^{12}$.

11 Sobre las elecciones y las prácticas electorales en Buenos Aires del período, véase Sábato, 2004. Para una reflexión sobre el fraude en América Latina del s. XIX, ver Posada-Carbó, 32/2 (Cambridge, 2000): 611-644, e Irurozqui, 2004.

12 Mitre, 1890: 490. 
El gobierno derrotó a los rebeldes por las armas, pero los nacionalistas siguieron impugnando la legitimidad del sistema, se abstuvieron de participar de las elecciones siguientes y amenazaron con volver a levantarse. La salida ideada por Avellaneda fue la de forjar, en 1877, una «conciliación» de partidos, que incluyó - entre otras medidas - la incorporación al gabinete de conocidos dirigentes mitristas y la presentación de listas comunes para las elecciones legislativas así como una fórmula acordada para la gobernación de Buenos Aires. Se buscó así evitar la inestabilidad del sistema a través de un mecanismo que no era nuevo: la eliminación de la competencia electoral a través del acuerdo previo entre cúpulas. La operación fue relativamente exitosa, aunque no alcanzó para disciplinar al conjunto de los dos partidos - autonomistas y nacionalistas-, pues algunos grupos dentro de ellos se resistieron a la propuesta conciliada y jugaron sus propias cartas.

Hacia 1879, sin embargo, esa política estaba agonizante. El gobernador Tejedor, producto de la conciliación, perdió apoyos en la legislatura y las elecciones de ese año para diputados y senadores bonaerenses le fueron adversas. Ese resultado era, según denunciaban sus partidarios, producto de la manipulación instrumentada por sus enemigos en el propio autonomismo. La referencia al «fraude» estuvo, como se ve, a la orden del día, actualizada ante cada elección, no sólo en Buenos Aires sino también en el resto de las provincias, donde el roquismo afirmaba su poder. El discurso arriba citado de Tejedor no innovaba; volvía sobre el mismo tema que ahora se planteaba en otra escala, la de la futura elección presidencial.

La confirmación de la candidatura de Roca y los apoyos de todo tipo que recibieron sus partidarios a través del gobierno nacional reforzaron las denuncias. A raíz de un episodio de esa índole, renunció a su cargo el ministro del Interior, Saturnino Laspiur, de origen mitrista y acompañante de Tejedor en la fórmula. En carta a Avellaneda, lo acusaba de abandonar la política de conciliación en apoyo de un candidato partidario: «Nunca le perdonará la República Argentina que Ud. no haya querido salvar sus libertades, y el país entero en medio de la lucha a que Ud. lo lleva protegiendo una candidatura que no tiene otros sostenedores que las armas de la Nación y gobernadores de provincias que se han alzado contra el poder» ${ }^{13}$.

También el gobernador porteño sería objeto de impugnación. Ante la proclamación de su candidatura, las dos cámaras de la legislatura provincial emitieron votos de censura por la afiliación pública de Tejedor a un partido político. La declaración propuesta por Diputados abordaba, precisamente, el tema

13 Citado en Galíndez, 1945: 101, nota 2. 
electoral en su artículo $1 .^{\circ}:$ «... en el deber de velar por la conservación de la paz, de las instituciones y del libre derecho de sufragio, emplearán [las cámaras] todos los medios que la Constitución autorize y las circunstancias aconsejen a fin de evitar que el Gobernador de la Provincia haga pesar la influencia de los elementos oficiales que dirije, en los actos electorales á que él fuere convocado» ${ }^{14}$.

Este contrapunto referido al lugar que las autoridades nacional y provincial ocuparían en la lucha electoral puso en circulación un primer motivo, el del fraude, que abonaría la confrontación. Las acusaciones mutuas en torno al mismo pronto abrieron el espacio a otras cuestiones.

\section{LA FUERZA MILITAR}

Desde que fuera propuesta, la candidatura de Roca fue asociada por sus opositores a su poder militar. Si bien había tejido una red de apoyos políticos en todo el Interior que le fueron decisivos a la hora de conquistar la nominación, su control del ejército - producto tanto de su trayectoria en la institución como de su lugar como ministro de guerra de Avellaneda - aparecía como el dato clave en la conquista partidaria de las «situaciones provinciales». En las palabras citadas de Laspiur, era el candidato apoyado «por las armas de la Nación». Para ganarle la elección parecía necesario, por lo tanto, resistir ese poder. Y los conciliados pronto recurrieron a una vía conocida, la de organizar sus propias fuerzas.

El diario mitrista La Nación lo proponía sin rodeos: «No se puede fiar solo en la fuerza del derecho, y cuando los poderes protectores del derecho y del órden se convierten en cabeza de bandos ó clubs electorales opresores de las libertades públicas, hay que pensar en que se necesitan medios eficaces para mantener el derecho. La ciudad de Buenos Aires tiene un número de electores,... que pueden formar un poder, tan grande, que no se han de atrever á impedir el libre ejercicio del voto. Pero para esto se necesita que cada elector sea un brazo armado, que sepa usar de su arma convenientemente...» $\rangle^{15}$.

Esta apelación no fue apenas una bravata de la prensa; se hacía eco, en realidad, de medidas ya tomadas por el gobernador y su gente. En primer lugar, a comienzos de septiembre, Tejedor convocó por decreto a la Guardia Nacional a ejercicios doctrinales en la ciudad y a la organización activa en doce distritos de la campaña (donde afectaba unos cincuenta mil hombres), designó a los je-

14 Citado en Sanucci, 1959: 56, nota 15.

15 La Nación, Buenos Aires, 16 de octubre de 1879 (el énfasis es mío). 
fes respectivos y creo la Comandancia general y un Estado Mayor. El gobierno nacional reaccionó y ordenó suspender esas medidas, lo que dio lugar a un fuerte intercambio entre el gobernador Tejedor y el nuevo ministro del Interior Sarmiento y a un intenso debate público en torno al tema. Mientras el primero sostenía la potestad de las provincias de movilizar a sus milicias, el segundo afirmaba «la organización de la Guardia Nacional y su reglamentación pertenecen solamente al Congreso» ${ }^{16}$.

Se pusieron así en escena dos concepciones diferentes acerca de la organización y el control sobre los recursos militares y del papel que el Estado central y las provincias tenían en relación con el uso legítimo de la fuerza. Según el sistema vigente desde la década del cincuenta, el Ejército Nacional estaba compuesto por el ejército de línea y la Guardia Nacional. El primero era de índole profesional y operaba bajo la comandancia suprema del presidente de la República. La Guardia, en cambio, funcionaba como una reserva miliciana de aquél, fundada sobre el principio del ciudadano en armas e integrada por todos los argentinos adultos. La coexistencia entre estas dos instituciones no fue fácil, pues si bien cada una tenía fines específicos definidos por la legislación, en los hechos sus competencias se superponían. Representaban, además, dos modelos diferentes de organización militar - fuerzas profesionales vs. milicias de ciudadanos - y de concebir la defensa y el poder del Estado, pues si bien en última instancia las dos debían responder al mismo comando nacional, en la práctica la Guardia había sido en general controlada por los gobiernos provinciales. Era ese control el que se puso en juego en los debates de septiembre de $1879^{17}$.

Para Tejedor, ante los «temores de una candidatura militar que tiene en sus manos el Ejército», el gobierno de la provincia tenía el «derecho y el deber de tranquilizar el ánimo de sus habitantes, encargando á ellos mismos la vigilancia de sus libertades» ${ }^{18}$. A esto respondió el Ejecutivo nacional con el decreto arriba mencionado y, finalmente, la movilización de la Guardia de Buenos Aires fue prohibida por ley. En su sanción, sin embargo, no primaron los argumentos que había esgrimido Sarmiento, ya que no hubo acuerdo en el Congreso ni en la Legislatura para cercenar la potestad de los gobiernos provinciales en relación a las milicias, y fueron otros los mecanismos legales que se utilizaron para impedir a Tejedor echar mano a ese recurso ${ }^{19}$. De todas formas, ante

16 Sábato, 2008; la cita en Mendizábal, 1881: 21.

17 He desarrollado este tema en Sábato 70 (Madrid, 2008): 93-114.

18 Citado en Mendizábal, 1881: 32.

19 La mencionada ley se limitó a prohibir el entrenamiento de las Guardias Nacionales en las provincias durante los tres meses anteriores y los posteriores a la elección nacional. 
esa prohibición, los porteños buscaron una segunda vía: la convocatoria a la población a organizarse en batallones de voluntarios.

La iniciativa correspondió a dirigentes políticos conciliados, entre los cuales se contaban algunos ex comandantes de la Guardia y oficiales del ejército de línea, quienes crearon el Tiro Nacional de Buenos Aires y la sociedad de Bomberos Voluntarios, asociaciones civiles que sirvieron de base para la organización de los batallones. El gobernador apoyó esa propuesta pues, como dijo, si bien estas sociedades legalmente eran «menos que la milicia... realmente era[n] mas. Era el pueblo que se manifestaba en toda su grandeza, que presentía la lucha y se preparaba» ${ }^{20}$.

La convocatoria dio resultado y, en poco tiempo, miles de porteños respondieron al llamado y se unieron a las fuerzas voluntarias. Éstas tuvieron su sede en diferentes locales distribuidos por toda la ciudad, donde se daban cita para sus prácticas de entrenamiento. Los domingos hacían ejercicios en el parque de Palermo, en los márgenes del casco urbano, lugar que se convertía en cita obligada de los batallones y de un público que asistía fervoroso y festivo a sus despliegues de destreza militar. Luego llegaron las fiestas cívicas para recolectar fondos para armas y uniformes, que también reunían a porteños y porteñas entusiastas. Ante esos despliegues, se quejaba el diario antitejedorista La Pampa: «Empezamos con la jarana de los tiradores y de los bomberos, y vamos concluyendo por el hecho gravísimo de que a cualquier Perico de los palotes que se le ocurra, levanta un batallón en cada barrio, en cada manzana, reúne candidatos a servir de carne de cañón, pide suscripciones y compra uniformes y remingtons y los hace sus soldados $»^{21}$.

Con argumentos más sesudos, el presidente Avellaneda dirigió un manifiesto a sus «conciudadanos» en los que expresó su alarma ante el hecho de que «los partidos se arman... organizando batallones que se pasean por las calles con el fusil al hombro y enarbolando la bandera nacional». Afirmó entonces que el mantenimiento de la paz pública de la Nación correspondía al ejército, pues «no hay... otro portador de armas, bajo una organización pública, sino el soldado... y su voluntad desaparece ante la obediencia que es la regla de su conducta... Esta es la regla universal que los pueblos han erigido para no caer víctimas de la fuerza». Se preguntaba retóricamente «si hay un lugar en la tierra donde exista una sociedad organizada y sea permitida la reunión de fuerzas armadas, sin ley, sin disciplina, sin el precepto de la obediencia y sin jefes que la impongan con un mandato público, responsable y reconocido». De se-

20 Tejedor, 1881: 70.

21 Sábato, 2008; la cita es de La Pampa, Buenos Aires, 6 de febrero de 1880. 
guir este camino, respondía, «quedará proclamado el gobierno de la fuerza» ${ }^{22}$. E invitaba a los ciudadanos a «suprimir las armas en presencia de la urna electoral». A continuación, dictó un decreto que prohibía en todo el país «las reuniones de ciudadanos armados, sea cual fuese el nombre que adopten...». En sus considerandos, se extendió sobre los derechos constitucionales de petición y de reunión, los cuales - decía - no pueden ejercerse «con las armas en la mano». En cuanto al artículo 21 de la carta magna, recordó parcialmente su texto, subrayando la segunda parte: «Todo ciudadano argentino está obligado a armarse en defensa de la patria..., conforme á las leyes que dicte el Congreso y á los decretos del Ejecutivo Nacional». Y puesto que por ley se había prohibido la reunión de fuerzas armadas que no fueran las del ejército hasta la transmisión del mando presidencial, quedaba claro que no sólo no se podía convocar a la Guardia Nacional sino que tampoco podían reunirse los batallones voluntarios ${ }^{23}$.

He aquí planteado un argumento contrario al que formulaban los porteños, quienes también recurrían al artículo 21, pero ponían en acento en la primera parte del mismo, que Avellaneda había citado en forma incompleta: "“Todo ciudadano argentino está obligado á armarse en defensa de la patria y de esta Constitución"», había recordado en enero el diario proconciliado La Libertad cuando cuestionó las disposiciones que limitaban ese precepto: «¿A qué queda entonces reducida la obligación y á la vez la garantía constitucional? Queda reducida a cero. Buenos Aires lo ha comprendido así y de ahí que espontáneamente sus hijos hayan corrido presurosos a tomar su lugar en las filas de los cuerpos voluntarios que se han organizado en salvaguarda de sus derechos. Se han armado en defensa de la Constitución» ${ }^{24}$.

La prohibición presidencial del 13 de febrero no hizo mella en los porteños, lo que dio lugar a una escalada de palabras y de acciones en la que las dos partes subían la apuesta en cada movimiento. Mientras los voluntarios siguieron movilizados y mostrándose armados por toda la ciudad, el gobierno nacional traía tropas del ejército hacia Buenos Aires. Los primeros se habían dado cita el domingo 15, como todas las semanas, para hacer su regular fiesta armada en Palermo. Muy temprano esa mañana, sin embargo, tres batallones de línea de infantería, dos regimientos de caballería y uno de artillería tomaron posesión del predio que ocupaba el Tiro Nacional. Ante el choque inminente, los

22 Avellaneda, 11, 1910: 393-398: «Manifiesto del Presidente de la República» (13 de febrero de 1880).

23 Ibidem, pp. 398-402.

24 La Libertad, Buenos Aires, 10 de enero de 1880. El énfasis es mío, para indicar la frase constitucional omitida en las consideraciones del decreto de Avellaneda y retomada por el diario. 
dirigentes porteñistas decidieron cambiar el despliegue previsto en Palermo por un «paseo» de los batallones por las calles de la ciudad. Esa tarde, catorce batallones y compañías de rifleros, tiradores y bomberos voluntarios desfilaron ante el aplauso de un público entusiasta. Era, según proclamó más tarde un militante de la causa, «el pueblo de Buenos Aires, que se había lanzado a las calles [...] para protestar... la conculcación de sus libertades». Sus opositores, en cambio, veían en la marcha apenas «un verdadero paseo carnavalesco» ${ }^{25}$.

Mientras tanto, en la casa de gobierno se sucedían febriles negociaciones para evitar el enfrentamiento, que culminaron en un armisticio y luego en un acuerdo de desarme. La situación se descomprimió apenas. El 20 de febrero, la ceremonia de disolución de las fuerzas porteñas dio lugar a una movilización pública con desfile de tropas y revista de las compañías por parte del gobernador, quien arengó a sus seguidores: «Ser guardia nacional es un honor. Vosotros sois más: sois los voluntarios de la República, armados para defender sus instituciones». Estas palabras, que podrían parecer destinadas al consuelo de quienes debían abandonar la empresa, fueron en cambio la confirmación de que Buenos Aires no habría de dejar las armas y de hecho, sus fuerzas voluntarias pronto volvieron a escena. También los nacionales siguieron reuniendo tropas en los alrededores de la ciudad, por lo que el clima de tensión irresuelta se mantuvo por varios meses.

\section{RESISTIR}

El panorama se complicó. Para los tejedoristas no se trataba ya sólo de denunciar el posible fraude y de contrarrestar una candidatura sostenida con apoyo militar a través de una movilización de los ciudadanos, sino de «resistir» activamente la «imposición» del gobierno nacional. Y esa resistencia podía llegar hasta el enfrentamiento armado.

Ya en enero La Nación advirtió: «[E]1 pueblo argentino en su gran mayoría no se deja despojar de ese derecho [de sufragio]... Si no es respetado, la resistencia y protesta es indudable. Un pueblo no se somete a perder el mas primordial de sus derechos sin resistir». Un mes más tarde su mensaje hacía referencia de manera explícita a «la necesidad de la resistencia armada, en defensa de los derechos agredidos y en salvaguardia de las libertades ultrajadas». Más radical era el Buenos Aires, que en ocasión de los sucesos de febrero se lamentaba porque «Hoy ha debido hacerse... la revolución... Nos hemos limitado á

25 Sábato, 2008, capítulo 2; las citas son de Gutiérrez, 1959: 64-65, y de La Pampa, Buenos Aires, 17 de febrero de 1880. 
quebrar moralmente al Gobierno Nacional en vez de hundirlo materialmente. Aún tenemos tiempo de remediar el mal. Los ciudadanos no deben dejar las armas... es posible y necesario salvar al país». Y más adelante agregaba: «El pueblo pide a gritos y sigue pidiendo la revolución [...] ¡No soltemos las armas! ¡Barricadas y cañones! ${ }^{26}$.

Esa apelación estaba en sintonía con una tradición política arraigada en el país y sobre todo, en la provincia. A esa tradición hacían referencia los conciliados cuando evocaban otras revoluciones, como la de 1810 y la de 1852 , como antecedentes gloriosos de sus acciones del presente ${ }^{27}$. Sin embargo, si bien arengaban a la población a armarse y mantenerse alerta para defender a la provincia de los avances del gobierno nacional, el llamado inicial de algunos a la «revolución» pronto fue cediendo lugar a una apelación más difundida a la «resistencia». Todos los preparativos se hacían en su nombre. Se trataba de estar listos para defenderse, como lo explicaba La Nación después de los sucesos de febrero: «Estos hechos, que han sublevado la indignación patriótica, y la convicción de que las amenazas se traducirán tarde ó temprano en sucesos funestos y sangrientos, ha obligado al pueblo a armarse en su defensa... $\rangle^{28}$.

Mientras tanto, varias elecciones habían tenido lugar en Buenos Aires, con triunfo conciliado. La última, en abril, fue la de electores a presidente, que ganaron los roquistas en el resto del país (con excepción de Corrientes, aliada de los porteños). Pero Tejedor y los suyos no se dieron por vencidos y siguieron reclamando la renuncia del candidato a la vez que reforzaron su organización armada. En ocasión de la apertura de las sesiones legislativas, en un cuerpo que ahora tenía mayoría conciliada, Tejedor volvió a anunciar que «la solución en la cuestión presidencial no será impuesta por la fuerza al pueblo de Buenos Aires» y que mientras no se llegara a una transacción, era «preciso estar prestos para todo». Las cámaras apoyaron al gobernador aprobando varios proyectos referidos a la organización y equipamiento de las fuerzas provinciales, con lo que daban pruebas, según afirmaban en un comunicado, de «su inquebrantable resolución de preparar a Buenos Aires virilmente para la resistencia...». Por su parte, decían, el gobernador podía así «seguir adelante con la sana política que garantiza los respetos y el acatamiento de la Autoridad Nacional, al mismo tiempo que salva la dignidad y las prerrogativas autonómicas de los

26 La Nación, Buenos Aires, 6 de enero de 1880 y 17 de febrero de 1880; Buenos Aires, Buenos Aires, 17 de febrero de 1880.

27 La fecha de 1874 era más controvertida, pues refería al levantamiento de los nacionalistas contra el autonomismo oficial y no podía ser reivindicada por quienes, provenientes de ese tronco, ahora eran aliados de los primeros en la «defensa» de la provincia.

${ }^{28}$ La Nación, Buenos Aires, 17 de enero de 1880. 
Estados Federales que forman la República». De esta manera, si por una parte todas las actitudes y las acciones de los conciliados y sus seguidores eran de confrontación con el gobierno nacional, por la otra, insistían en que éstas eran de índole estrictamente defensiva ${ }^{29}$.

El ingreso de armas para los porteños, cuya importación había sido prohibida por la autoridad nacional, desató la última etapa de la crisis. Las fuerzas porteñistas custodiaron el desembarco de los fusiles y lo defendieron frente a buques de la escuadra oficial. Ante esos hechos, el Presidente abandonó la ciudad y se trasladó al vecino pueblo de Belgrano, donde instaló la sede del gobierno y aceleró los preparativos militares. En la proclama del 3 de junio acusó a Tejedor de haberse «alzado abiertamente en armas contra las leyes de la Nación y sus Poderes Públicos», de «rebelión manifiesta» y de «insurrección», y anunció que iba a movilizar hombres y armas para hacer respetar y cumplir esas leyes. El gobernador respondió negando que su actitud implicara un «alzamiento...» y menos una «rebelión manifiesta» y reafirmando su respeto a las autoridades legítimas de la República. Objetaba, sin embargo, el traslado del presidente a Belgrano, actitud que lo obligaba «a dictar medidas de seguri$\mathrm{dad} »^{30}$.

Avellaneda no volvió atrás y consideró al gobierno de la provincia en rebelión. Tejedor, por su parte, convocó a la Guardia Nacional (desobedeciendo así la ley que lo prohibía) pero fijó los límites de la movilización en marcha. Ésta tenía por objetivo «defender [las] instituciones y no... atacar las leyes y autoridades nacionales». Y agregó: «Mientras no se haga el primer tiro por las fuerzas nacionales o provoquen éstas la primera batalla, el Presidente de la República es el funcionario supremo». Insistió así en su política de resistencia. Según su testimonio posterior, creía que la resistencia sostenida de Buenos Aires y su aliada Corrientes bastaba para «salvar los derechos federales de los Estados». No aceptaba «el rol de rebelde» ${ }^{31}$.

En todo este último intercambio, como se ve, el término «revolución» estuvo ausente. Tanto Avellaneda como Tejedor mencionaron con connotaciones negativas las palabras «insurrección» y «rebeldía», pero mientras para el primero estas palabras se aplicaban perfectamente a la «resistencia» tejedorista, para el gobernador y sus huestes, no se podía hablar de rebelión si lo que estaba en juego era la defensa de la libertad. Este derecho fue impugnado por el gobierno nacional, para quien insurrección y rebeldía no se diferenciaban de

\footnotetext{
29 Tejedor, 1881: 102; Mendizábal, 1881: 270.

30 Galíndez, 1945: 270-274.

31 Tejedor, 1881: 120-127.
} 
revolución y de resistencia, o al menos, del uso que de ellas hacían los porteños.

\section{UNA TRADICIÓN IMPUGNADA}

Este episodio de 1880 puede sin duda ponerse en serie con otros similares, en particular en lo que he llamado en otro lugar el «ciclo revolucionario» de Buenos Aires ${ }^{32}$. A diferencia de lo ocurrido antes, en 1874, y después, en 1890 , en este caso no hubo proclamas que anunciaran una «revolución», pero el movimiento que se gestó compartía muchas de las características básicas de los otros dos y, sobre todo, como vimos, su fundamentación en el derecho a resistir «la imposición». La preferencia de los conciliados, y sobre todo de Tejedor, por el término «resistencia» y el escaso uso que en el ochenta ellos hicieron de la palabra «revolución» posiblemente respondiera más a razones coyunturales que a una transformación sustantiva en el lenguaje político. Sin embargo, éste también estaba experimentando cambios importantes que llevaron a nuevas articulaciones conceptuales y contribuyeron a dar nuevos sentidos a aquel término.

Hemos mencionado ya el impacto de la revolución nacionalista de 1874 contra el gobierno autonomista en la vida política de esos años. Es probable que Tejedor y otros autonomistas ahora aliados de los nacionalistas en contra de muchos de sus viejos compañeros buscaran disociar su movimiento de aquella revolución a la que habían combatido. Mientras los diarios que, como La Nación, habían apoyado el alzamiento, se referían con frecuencia al setenta y cuatro como un antecedente virtuoso, los de simpatía autonomista tejedorista guardaban un prudente silencio respecto de esa fecha ${ }^{33}$. En ese contexto, el término mismo de «revolución» podía resultar irritante para muchos porteños que, sin embargo, se sentían convocados por la causa de Buenos Aires y estaban dispuestos a acudir al llamado de los dirigentes conciliados. «Resistencia», en cambio, no tenía esas connotaciones y por otra parte, hacía referencia a los fundamentos considerados legítimos para la reacción armada.

Para Tejedor, sin embargo, la opción no parece haber sido exclusivamente retórica. Como hemos visto, sus órdenes respecto a no tirar el primer tiro, su negativa a atacar antes de ser atacado - que le trajo no pocos enfrentamientos con civiles y militares de sus propias filas - y la forma en que luego condujo

\footnotetext{
32 Sábato, 23 (Buenos Aires 2002): 149-169.

33 Véase, por ejemplo, «La cuestión electoral», La Nación, Buenos Aires, 6 de enero de 1880 .
} 
las operaciones de guerra se pueden entender mejor en función de su decisión de resistir más que de asumir la iniciativa armada. Se trataba, para él, de $L a$ defensa de Buenos Aires, como indicara el título del libro que poco después escribiera sobre los hechos del ochenta.

Estas reticencias frente al término «revolución» no implicaban, sin embargo, un cuestionamiento a la tradición revolucionaria, ni en sus fundamentos ni en sus formas. La reivindicación del derecho ciudadano a levantarse en armas ante un gobierno despótico era no solo patrimonio de los porteños rebeldes, sino que se observa también entre sus opositores. Éstos impugnaban la actitud porteñista pero sin cuestionar el derecho a la resistencia. Sus argumentos variaban. Así, para La República, no era el pueblo de Buenos Aires el que se levantaba sino «una fracción, un círculo, una agrupación del pueblo» y agregaba que «no se engañen los agitadores. La excitación que domina sus cerebros les hace ver un pueblo en masa, donde sólo existe un círculo anárquico, envalentonado por su alianza transitoria con el Poder». La Pampa, por su parte, llamaba a reflexionar sobre los peligros a que se exponían quienes «se dejan seducir por los flojonazos que los arman...», pues irían a una segura derrota. No podrían los tiradores y bomberos contra el ejército de línea, sostenía, no contaban con las armas ni con el entrenamiento necesarios y tampoco existía un caudillo para «dirigir y entusiasmar las masas del pueblo militarizadas». Y concluía: «¡Basta ya de hacerse matar como tontos por los intereses de los más pillos!» El problema no estaba en la revolución, entonces, sino en su segura derrota $^{34}$.

Junto con estos mensajes críticos de esta revolución, circulaban también otros que ponían en tela de juicio toda revolución. Esta verdadera institución de la vida política argentina de entonces fue seriamente cuestionada, y con ella, el derecho de los ciudadanos a armarse para resistir al despotismo, que le había servido de fundamento doctrinario. En términos prácticos, se sostenía que el gobierno central era el único que podía recurrir al uso de la fuerza y el ejército nacional la institución encargada de llevar las armas. En estos meses abundaron los discursos en ese sentido y también las acciones tendientes a hacer cumplir estos principios. Las palabras de Sarmiento y del presidente Avellaneda fueron, quizá, las más consistentes en este sentido.

Desde su asunción como ministro del interior, el primero había intervenido para impedir la movilización de las milicias porteñas. Sus palabras adquirieron un tono de denuncia más general cuando se dirigió al Senado luego de presen-

34 La República, Buenos Aires, 28 de febrero de 1880; La Pampa, Buenos Aires, 5 de febrero de 1880 . 
tar al presidente su renuncia. Entonces dijo: «Un gobernador, señor, no se garante á sí mismo; un pueblo no se garantiza á sí mismo la libertad. Un gobernador levantando ejército para garantir las libertades de su pueblo... ¡Mentira! ¡Mentira! Para eso está el gobierno nacional; esta es una nación y solo el gobierno nacional puede dar garantías; y si yerra, si comete crímenes, son los crímenes del error del soberano que crea la Constitución, y en ella está el último remedio del mal. La opinión pública, el trabajo lento del tiempo, el valor de los ciudadanos pone por otra parte remedio á esos errores, que no lo han de dar las revoluciones.... $\rangle^{35}$.

He citado este párrafo in extenso pues desgrana varios de los argumentos que sirvieron para impugnar las revoluciones: el cuestionamiento al precepto de que el pueblo debía garantizar su libertad, la mentira que encerraba el reclamo de los gobernadores de provincia que se armaban en nombre de ese pueblo, la afirmación de que esa defensa correspondía exclusivamente al gobierno nacional, la convicción de que si éste equivocara su rumbo, debía recurrirse a la constitución como remedio y a la opinión como medio, pero nunca a la revolución. Buscaba deslegitimar así las acciones que entonces tenían lugar en la República (y no sólo en Buenos Aires) destinadas a controlar la situación electoral y lo hacía a través de una crítica de fondo a la práctica revolucionaria.

La palabra de Avellaneda era, en general, menos contundente que la de su ministro, pero en este caso no dejó de expresar una y otra vez su censura a dicha práctica. En un artículo periodístico de octubre de 1879, bajo el título «No hay revolución», volvió sobre la experiencia del setenta y cuatro: «Hágase nuevamente otra revolución septembrista ${ }^{36}$ por motivos electorales y la revolución entra ya en la vida común, y resultará establecido que cada seis años, al inaugurarse un período presidencial, el país se envolverá en la guerra civil». Avanzó luego: «Esto significa decir que habremos dejado de ser una Nación constituida para envolvernos en la anarquía y caer después á los pies de una Dictadura, que contará sus días de dominación por el brillo de su sable... He ahí los resultados de la política revolucionaria.... ${ }^{37}$.

Este texto pone en primer plano un tópico que Avellaneda reiteraría a lo largo del año siguiente: la motivación electoral de las revoluciones. Sus resultados serían, además, contrarios a los principios invocados para fundamentarlas: en lugar de fortalecer la libertad, fomentarían la dictadura. Finalmente, no

35 Sarmiento, XIV, 1917: 393 (septiembre/octubre de 1879).

36 La revolución de 1874 tuvo lugar en el mes de septiembre.

37 Avellaneda, 1910: 351-352. 
había nada que distinguiera la revolución de la guerra civil, o como diría luego, la insurrección, la revuelta y la anarquía.

Otro pilar de su postura se relacionó con la fuerza militar y su indispensable control por parte del Estado. «Establézcase que los individuos puedan armarse colectivamente, constituir batallones y formar un ejército, y quedará proclamado el gobierno de la fuerza.» Tales palabras se encuentran en el manifiesto del 13 de febrero, arriba mencionado, en que reaccionó frente a la movilización de los voluntarios de Buenos Aires. Ese mismo día, en los considerandos de su decreto prohibiendo las reuniones de ciudadanos armados dijo: «Llevar públicamente armas, organizar y reunir bajo un sistema á los que las llevan, formar batallones ó un ejército, es precisamente el atributo esencial del Gobierno, donde quiera que haya una sociedad organizada» ${ }^{38}$.

\section{LA DISPUTA POR EL SENTIDO}

El conflicto desatado en 1880 fue así la ocasión para la puesta en escena de diferentes formas de entender el uso de la fuerza militar y el derecho de rebelión. Esa contienda no sólo giró en torno de quién habría de ser el próximo presidente y de qué sector partidario habría de imponerse, sino que involucró centralmente la cuestión del modelo de Estado y los modos de hacer política. Por lo tanto, se dio tanto en el terreno de la práctica como de las palabras y fue una lucha por el poder a la vez que una disputa por el sentido de la república.

Dos proclamas emitidas muy poco después de los sangrientos combates de junio muestran hasta qué punto el enfrentamiento en el campo de batalla se prolongó en el de los discursos. «iHonor a los defensores de Buenos Aires!» encabezó el ministro de milicias Gainza su proclama dirigida a las tropas bajo su comando y en ella desplegó los motivos centrales de la retórica republicana y porteñista sobre la que se fundaba la revolución. «La resistencia de la provincia se ha iniciado con dos combates sangrientos en que os habéis cubierto de gloria, luchando, venciendo y muriendo como solo saben hacerlo los hombres libres. [...] Las instituciones de la República os agradecen tanta abnegación y patriotismo [...]. La heroica ciudad que resistió en épocas remotas el asalto de naciones poderosas, sabrá hoy como entonces cubrirse de gloria...» Y terminaba: «Que nuestra divisa sea: Ser libres ó morir», consigna que sintetizaba todo un programa: el que había servido de bandera en todas las revoluciones que se hacían en nombre del derecho y del deber de los ciudadanos de

\footnotetext{
38 Ibidem: 396 у 400.
} 
resistir al despotismo. En este caso, como vimos, se invocó el cercenamiento de la libertad electoral a través de la imposición de un candidato «oficial», que era, además, un candidato «militar», para justificar la movilización armada de la ciudadanía de la provincia. Los intentos del gobierno nacional de frenar esa movilización a través de la ley y de la fuerza reforzaron los argumentos porteños en favor de una resistencia activa a lo que consideraban una imposición inadmisible.

Para el presidente Avellaneda, en cambio, esos argumentos carecían de todo fundamento y sus discursos insistieron en la defensa del poder central y la condena a toda revolución. Esos mismos motivos pautaron la proclama de triunfo que hizo a sus tropas y que, como un eco del saludo de Gainza a los defensores de Buenos Aires, encabezó con las palabras «¡Honor al Ejército!». En ellas, sin embargo, el término honor cobraba un sentido diferente, pues se asociaba a la defensa de la patria, la consolidación de las instituciones, y el afianzamiento del gobierno nacional y de su autoridad. Los «Jefes, Oficiales, Soldados y Guardias Nacionales de todas las provincias» no habían derramado en vano su sangre, pues los resultados eran claros: «Toda la República hablará en breve de vuestra obra, que será la consolidación de nuestras instituciones, - el prevalecimiento del Gobierno Nacional como principio en los espíritus y como autoridad en los hechos...- y la supresión, por fin, en la rebelión presente de todas las rebeliones futuras, puesto que se habrá evidenciado para siempre su imposibilidad». La práctica de la revolución quedaría así erradicada para siempre; pronto el «episodio doloroso» habría terminado y «la Nación proseguirá por las vías pacíficas su desenvolvimiento poderoso» ${ }^{39}$.

Ese pronóstico de Avellaneda no se habría de cumplir tan fácilmente y otras revoluciones tuvieron lugar en lo que quedaba del siglo en la Argentina. Pero sus palabras referían a un conjunto de tópicos que perfilaban un cambio importante en relación con el lenguaje político que había predominado en las décadas anteriores y que todavía enmarcaba buena parte de la retórica política vigente. Para 1880, el concepto de «revolución» tenía vigencia plena en esa retórica, pero admitía diferentes versiones que le imprimían un carácter inestable, y la convertían en una palabra en disputa ${ }^{40}$. Había dejado de estar claramente inscripta en un repertorio discursivo articulado que le otorgaba un significado preciso y era ese conjunto mismo el que ahora aparecía cuestionado. En dicho marco, la preferencia retórica por la «resistencia» frente a la «revolución» que mostraron aún quienes, como los porteños rebeldes, seguían actuan-

\footnotetext{
39 Ibidem: 439-440.

40 Acerca de la inestabilidad de los conceptos y la temporalidad de las formaciones conceptuales véase Palti, 2007.
} 
do según aquel repertorio, tal vez pueda leerse como un síntoma de esa inestabilidad y de los reacomodos que resultaban de ella.

Al mismo tiempo, en el terreno de las prácticas, la revolución siguió integrando el catálogo de acciones políticas posibles durante varias décadas. $\mathrm{Si}$ bien su legitimidad estuvo, a partir esos años, fuertemente cuestionada, y fue cada vez más difícil montar revoluciones y sobre todo ganarlas, sólo hacia principios del siglo XX quedaron, en su forma decimonónica, erradicadas del panorama político nacional.

\section{BIBLIOGRAFÍA}

Alonso, Paula, Entre la revolución y las urnas. Los orígenes de la Unión Cívica Radical y la política argentina en los años 90, Buenos Aires, 2000.

Avellaneda, Nicolás, Escritos y discursos, volumen 11, Buenos Aires, Compañía Sud-americana de Billetes de Banco, 1910.

Botana, Natalio, El orden conservador. La politica argentina entre 1880 y 1916, Buenos Aires, Sudamericana, 1977.

Botana, Natalio y Ezequiel Gallo, De la república posible a la república verdadera (1880-1910), Buenos Aires, Ariel, 1997.

Chust, Manuel y Juan Marchena (eds.), Las armas de la Nación. Independencia y ciudadanía en Hispanoamérica (1750-1850), Madrid/Fráncfort, Iberoamericana Vervuert, 2007.

Dunkerley, James (ed.), Studies in the Formation of the Nation State in Latin Ameri$c a$, Londres, ILAS, 2002.

Earle, Rebecca (ed.), Rumours of War. Civil Conflict in Nineteenth-Century Latin America, Londres, ILAS, 2000.

Forte, Riccardo y Guillermo Guajardo (coords.), Consenso y coacción. Estado e instrumentos de control político y social en México y América Latina (siglos XIX y $X X$ ), México, El Colegio de México y el Colegio Mexiquense, 2000.

Galíndez, Bartolomé, Historia política argentina. La revolución del 80, Buenos Aires, Imprenta y Casa Editora Coni, 1945.

Gutiérrez, Eduardo, La muerte de Buenos Aires, Buenos Aires, Hachette, 1959 [texto publicado originalmente en 1882].

Halperin Donghi, Tulio, Proyecto y construcción de una nación (Argentina 1846-1880), Caracas, Biblioteca de Ayacucho, 1980.

Irurozqui, Marta, La ciudadanía en debate en América Latina, Documento de Trabajo 139, Lima, Instituto de Estudios Peruanos, 2004. 
Mitre, Bartolomé, Arengas, Buenos Aires, 1890.

Malamud, Carlos, «La restauración del orden. Represión y amnistía en las revoluciones argentinas de 1890 y 1893», Eduardo Posada-Carbó (ed.), In Search of a New Order: Essays on the Politics and Society of Nineteenth-Century Latin America, Londres, ILAS, 1998: 107-130.

Malamud, Carlos, «Elecciones, política y violencia. Las revoluciones argentinas de 1890 y 1893», Riccardo Forte y Guillermo Guajardo (coords.), Consenso y coacción. Estado e instrumentos de control político y social en México y América Latina (siglos XIX y XX), México, El Colegio de México y el Colegio Mexiquense, 2000: 9-37.

Malamud, Carlos, «The Origins of Revolution in Nineteenth-Century Argentina», Rebecca Earle (ed.), Rumours of War. Civil Conflict in Nineteenth-Century Latin America, Londres, ILAS, 2000a: 29-48.

Malamud, Carlos y Carlos Dardé (eds.), Violencia y legitimidad. Política y revoluciones en España y América Latina, 1840-1910, Santander, Universidad de Cantabria, 2004.

Mendizábal, Ernesto, Historia de un crímen, Buenos Aires, Imprenta de Pablo E. Coni, 1881.

Oszlak, Óscar, La formación del estado argentino, Buenos Aires, Ed. de Belgrano, 1982

Paltí, Elías, El tiempo de la politica. El siglo XIX reconsiderado, Buenos Aires, Siglo XXI, 2007.

Posada-Carbó, Eduardo, «Electoral Juggling: A Comparative History of the Corruption of Suffrage in Latin America, 1830-1930», Journal of Latin American Studies, 32/2 (Cambridge, 2000): 611-644.

Sábato, Hilda, «El ciudadano en armas: violencia política en Buenos Aires (1852-1890)», Entrepasados, XII/23 (Buenos Aires, 2002): 149-169.

Sábato, Hilda, La política en las calles. Entre el voto y la movilización: Buenos Aires, 1862-1880, Buenos Aires, Sudamericana, 1998 (segunda edición: Bernal, Universidad Nacional de Quilmes, 2004).

Sábato, Hilda, «Milicias, ciudadanía y revolución: el ocaso de una tradición política. Argentina, 1880», Ayer. Revista de Historia Contemporánea, núm. 70, Madrid, 2008 (2): 93-114.

Sábato, Hilda, Buenos Aires en armas. La revolución de 1880, Buenos Aires, Siglo XXI, 2008.

Sanucci, Lía, La renovación presidencial de 1880, La Plata, Universidad Nacional de La Plata, 1959. 
Sarmiento, Domingo Faustino, Obras escogidas, Tomo XIV, Discursos parlamentarios, tercer volumen, Buenos Aires, Librería «La Facultad», 1917 (septiembre/octubre de 1879).

Tejedor, Carlos, La defensa de Buenos Aires, Buenos Aires, 1881.

\section{«RESISTING IMPOSITIONS»: REVOLUTION, CITIZENSHIP AND REPUBLIC IN ARGENTINA IN 1880}

The revolution of 1880 in Buenos Aires was a key episode in Argentine history. This work focuses upon one aspect of that conflict: the controversy that surrounded the use of the term "revolution» in the context of the prevailing political languages. In order to explore this dimension of the dispute, the article analyzes the main arguments displayed by the revolutionaries to justify their action, as well as those used by their opponents to repress the movement.

Key WORDs: Revolution, Political Citizenship, Armed Forces, Republic, Political lenguages. 